\section{An Alu polymorphism intragenic to the TP53 gene}

\author{
P.A.Futreal ${ }^{1}$, J.C.Barrett and R.W.Wiseman \\ Lab. of Molecular Carcinogenesis, National Institute of \\ Environmental Health Sciences, NIH, Research Triangle \\ Park, NC 27709 and 'Dept. of Pathology, University of \\ North Carolina, Chapel Hill, NC 27599, USA
}

Source/Description: An Alu sequence with an (AAAAT) ${ }_{8}$ at the $3^{\prime}$ end was identified in the first intron of the TP53 gene at position 8703 of EMBL accession no. X54156 (1). Primers that uniquely amplified this Alu element were designed for the polymerase chain reaction. The simple sequence repeat polymorphism was detected by primer extension of a radiolabeled consensus Alu primer (2). The predicted length of the radiolabeled product for the (AAAAT) $)_{8}$ repeat was $120 \mathrm{bp}$.

Primer Sequences: P53ivs1a: GCACTTTCCTCAACTCTACA; P53ivs 1b: AACAGCTCCTTTAATGGCAG; ALE3 (consensus Alu primer, ref. 3): $\mathrm{CCA}(\mathrm{C} / \mathrm{T}) \mathrm{TGCACTCCAGCCTGGG.}$ ALE3 was $95 \%$ homologous to the TP53 Alu sequence.

Frequency: Estimated from 50 chromosomes of unrelated individuals. Observed heterozygosity $=0.68$

Allele (bp) Frequency

K1 $140 \quad 0.02$

$\mathrm{K} 2130 \quad 0.04$

K3 $125 \quad 0.22$

K4 $120 \quad 0.46$

K5 $115 \quad 0.20$

K6 $105 \quad 0.06$

Chromosomal Location: The p53 gene has been assigned to $17 \mathrm{p} 13.1$ (4).

Mendelian Inheritance: Co-dominant segregation was observed in a 12 member, 3 generation pedigree.

PCR Conditions: Conditions for the initial amplification were 50 ng genomic DNA, $1 \mu \mathrm{M}$ each of P53ivsla and P53ivs1b, $1 \times \mathrm{PCR}$ buffer (Perkin Elmer Cetus), $200 \mu \mathrm{M}$ dNTPs, and 0.5 units of Amplitaq DNA polymerase in a $20 \mu$ l reaction volume. The reactions were processed through 27 cycles of $1 \mathrm{~min}$ at $94^{\circ} \mathrm{C}$, $1 \mathrm{~min}$ at $55^{\circ} \mathrm{C}$, and $1 \mathrm{~min}$ at $72^{\circ} \mathrm{C}$. One $\mu \mathrm{l}$ of this reaction was extended in a $20 \mu \mathrm{l}$ reaction containing $1 \mu \mathrm{M}$ ALE3 labeled with T4 polynucleotide kinase. This final cycle consisted of $1 \mathrm{~min}$ at $94^{\circ} \mathrm{C}, 2 \mathrm{~min}$ at $55^{\circ} \mathrm{C}$, and $3 \mathrm{~min}$ at $72^{\circ} \mathrm{C}$. Allele sizes were determined by comparison to $\mathrm{M} 13 \mathrm{mp} 18$ sequencing ladders on $6 \%$ denaturing polyacrylamide gels. The repeat sequence in X54156 was of the form (AAAAT) 8 .

Other Comments: This marker is useful for the detection of TP53 allele loss in tumors.

References: 1) Chumakov,P.M. et al. (1991) Nucl. Acids Res. 19, 4804. 2) Epstein,N. et al. (1990) Nucl. Acids Res. 18, 4634. 3) Cole,C.G. et al. (1991) Genomics 10, 816-826. 4) Van Tuinen,P. et al. (1988) Am. J. Hum. Genet. 43, 587-596.

\section{A new Taql RFLP within intron 2 of human dopamine D2 receptor gene (DRD2)}

A.Parsian, L.Fisher, K.L.O'Malley and R.D.Todd

Departments of Psychiatry, Genetics, and Anatomy and Neurobiology, Washington University School of Medicine, 4940 Audubon Avenue, St Louis, MO 63110, USA

Source/Description: Probe phD2-244 containing a $3.8 \mathrm{~kb}$ XbaI fragment inserted in the XbaI site of Bluescript. Insert contains all of exon 3 , about $150 \mathrm{bp}$ of intron 3 , and about $3 \mathrm{~kb}$ of intron 2 (1).

Polymorphism: TaqI identifies a two-allele polymorphism with fragments at $3.1 \mathrm{~kb}$ (D1) and 1.75 and 1.3 (D2). Constant fragments are at 1.4 and $0.8 \mathrm{~kb}$.

Frequency: Estimated in 39 unrelated Caucasians

D1: 0.61

D2: 0.39

Observed heterozygosity $=0.58$.

Chromosomal Location: Localized on chromosome 11 at q22-23 by in situ hybridization (2).

Mendelian Inheritance: Co-dominant segregation was observed in 20 informative Caucasian families (See Figure).

Availability: For collaborative studies, contact Dr R.D. Todd, Dept. of Psychiatry, Box 8134, Washington University School of Medicine, St Louis, MO 63110, USA.

Acknowledgements: This work was supported by USPHS grants MH 31302, MH 45019 and AA 08028.

References: 1) Gandelman et al. (1991) Neurochem. 56, 1024-1029. 2) Grandy et al. (1989) Am. J. Hum. Genet. 45, $778-785$.

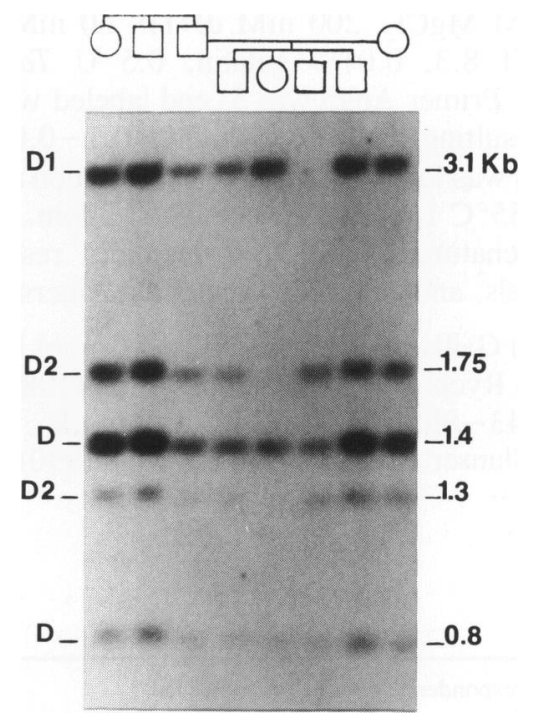

